\title{
Corrosion Inhibitor Potential of Four Phenyltetrazoles Derivatives using Density Functional Theory and Quantitative Structure-Activity Relationships Approach
}

\author{
*1 OGUNYEMI, BT; ${ }^{2}$ ADEJORO, IA \\ *1 Federal University Otuoke, Bayelsa State, Nigeria \\ ${ }^{2}$ University of Ibadan, Ibadan, Nigeria \\ *Corresponding Author Email: btogunyemi@yahoo.com
}

\begin{abstract}
The corrosion inhibition potential of four phenyltetrazole derivatives $\left(\mathrm{M}_{1-4}\right)$ were investigated by theoretical methods. The efficiency of corrosion inhibitors depends on many quantum chemical descriptors: chemical hardness, softness, electronegativity, dipole moments, molecular volume, surface area, as well as electronic orbital energies: $\mathrm{E}_{\text {номо }}$ (highest occupied molecular orbital energy); $\mathrm{E}_{\mathrm{LUMO}}$ (lowest unoccupied molecular orbital energy) and energy gap $(\Delta \mathrm{E})$ calculated from DFT approach. A statistical ordinary least square method was used to perform regression analysis that determined the correlations between the calculated descriptors and the experimental inhibition efficiency for phenyltetrazole derivatives while the QSAR model developed was used to predict their corrosion inhibition efficiency. The predicted corrosion inhibition efficiencies of the phenyltetrazoles derivatives correspond well to the experimental measurements. The correlation coefficient was 0.9984 and the root mean square error (\%), was 1.36 . With the embedded QSAR model, the corrosion inhibition efficiencies of two novel phenyltetrazole derivatives $\left(\mathrm{M}_{5-6}\right)$ were predicted.
\end{abstract}

\section{DOI: https://dx.doi.org/10.4314/jasem.v23i4.15}

Copyright: Copyright $@ 2019$ Ogunyemi and Adejoro. This is an open access article distributed under the Creative Commons Attribution License (CCL), which permits unrestricted use, distribution, and reproduction in any medium, provided the original work is properly cited.

Dates: Received: 21 February 2019; Revised: 19 March 2019; Accepted 12 April 2019

Keywords: Corrosion Inhibition, QSAR, Phenyltetrazole, DFT calculation

Protecting metal surfaces from corrosion is a very active and important industrial and scientific field of research. The use of inhibitor is one of the practical means of preventing corrosion (Kumpawat et al., 2010). In acidic media, inhibitors depressed the rate of corrosion by adhering to the surface of the metal forming a protective barrier against any corrosive agent in contact with the metal or change in the activation barriers of the anodic and cathodic reactions of the corrosion process (Ojo et al., 2018; Ebenso et al., 2010). The effectiveness of inhibitor against corrosion depends to a large on the extent of interaction between the inhibitor and the surface of the metal (Ergun et al., 2008). It was also observed that the adsorption of inhibitor on the metal surface depends on the electronic and structural properties of the inhibiting molecule (Kuznestov et al., 2016). As a result of these, several classes of organic compounds have been studied and utilized as inhibitors for metals in acid environments. These organic compounds have many advantages such as low price, ease of production and high inhibition efficiency (El kacimi et al., 2012). The presence of aromatic rings, conjugated double bonds, heteroatoms (nitrogen and/or sulfur) in their structures (El kacimi et al., 2017) has been reported to further enhance the effectiveness of these organic compounds as excellent corrosion inhibitors by reducing the active sites which lead to corrosion (ObiEgbedi et al., 2011). Free electron pairs in heteroatom or $\pi$ electrons are readily available to form covalent bonds and serve as the nucleophilic centers for inhibiting molecules which facilitate the adsorption process on the surface of a metal, whose atoms acts as electrophiles (Abboud et al., 2007). In search of suitable organic corrosion inhibitors, several researchers experimentally reported on the role of some azole compounds as inhibitors on various metal surfaces and in different environments (Ebenso et al., 2010; Adardour et al., 2013). Experimental tools are helpful in explaining the mechanism of inhibition, but they are often expensive and time-consuming. Continuous advances in hardware and software have opened doors for the powerful use of theoretical chemistry in corrosion inhibition studies. Several quantum-chemical and molecular modeling methods have been performed to relate the inhibitory effectiveness of inhibitors with their molecular properties. The use of theoretical parameters allows the characterization of molecular structures of inhibitors and suggests a mechanism for their interaction with metal surfaces (El Sayed et al., 2008). These quantum chemical methods have been combined with experimental methods to confirm the 
potential of triazole derivatives as corrosion inhibitors (Abdulazeez et al., 2016).

Recently, the inhibition of corrosion of certain phenyltetrazole derivatives have been studied experimentally (Khaled et al., 2009). The experimental work provides valuable information on the corrosion inhibition efficiency of phenyltetrazole, a thorough understanding of the inhibitory properties remains uncertain. Therefore, the main aim of this paper is to use quantum mechanical approach to calculate molecular reactivity descriptors that relate to the observed inhibition efficiencies of these phenyltetrazole derivatives namely: namely 5-phenyl1H-tetrazole $\left(\mathrm{M}_{1}\right)$, 5-(4- Chlorophenyl) 1-H- tetrazole $\left(\mathrm{M}_{2}\right)$, 5-(4-methoxyphenyl)-1H-tetrazole $\left(\mathrm{M}_{3}\right)$, 5-ptolyl-1H-tetrazole $\left(\mathrm{M}_{4}\right)$ as shown in Figure 1, and also to develop their quantitative structural activity relationship (QSAR) model from the calculated descriptors that could predict the observed inhibition efficiencies. The developed quantitative structural activity relationship (QSAR) model which can predict the inhibition efficiencies other derivatives such as 1Phenyl-1,2,3,4-tetrazole-5-thiol ( $\left.\mathrm{M}_{5}\right)$, 5-Benzylthio-1phenyl-1,2,3,4-tetrazole $\left(\mathrm{M}_{6}\right)$ yet to be determined experimentally.

Computational Details DFT Calculation The present calculations were performed using the SPATAN 10 software package (Shao et al., 2010). Geometric optimization was performed using DFT in conduction with Becke's three parameter exchange functional, B3 (Becke, 1988) associated with the gradient corrected correlation functional of Lee, Yang, and Parr, LYP (Lee, et al., 1988) and the 6-311 G(d,p) basis set. The dihedral angles bond angles and bond lengths were allowed to relax without constraints during geometric optimization. The stationary points were confirmed by analyzing the vibrational frequency to ensure that no imaginary frequency is present in the entire geometry. The Fukui functions were calculated using electron populations for neutral, cation and anion, phenyltetrazoles. Frontier molecular orbitals; (HOMO and LUMO) were used to predict the adsorption sites of the inhibiting molecule. The $\mathrm{E}_{\mathrm{HOMO}}$ and $\mathrm{E}_{\mathrm{LumO}}$ of the inhibiting molecule are related to the ionization potential (IP) and the electron affinity (EA), respectively using Koopman's theorem (Pearson, 1986) by the following relationships:

$$
\begin{aligned}
& I=-E_{\text {номо }} \\
& A=-E_{\text {LUмо }}
\end{aligned}
$$

The electronegativity, $\chi$, and the hardness, $\eta$, of the inhibiting molecule are given as (Parr and Pearson 1983):

$$
\chi=-\mu=\left(\frac{\delta \varepsilon}{\delta N}\right)_{v(r)}=-\frac{E_{L U M O}+E_{\text {Номо }}}{2}=\frac{I P+E A}{2}
$$

$$
\eta=\left(\frac{\delta \varepsilon^{2}}{\delta N^{2}}\right)_{v(r)}=\frac{E_{\text {LUMO }}+E_{\text {HOMO }}}{2}=\frac{I P-E A}{2}
$$

Furthermore, softness is defined as the inverse of the hardness value (Chirico and Gramatica, 2012):

$$
\sigma=\frac{1}{\eta}
$$

These reactivity descriptors have proven very useful in the theory of chemical reactivity. When two systems, the Fe and the inhibitor, are in contact with each other, the electrons from lower $\chi$ (inhibitor) flows to higher $\chi(\mathrm{Fe})$ until the chemical potential is equal.

The number of electron transferred $(\Delta N)$ is also estimated by the equation below (Pearson 1988):

$$
\Delta N=\frac{\chi_{F e}-\chi_{i n h}}{2\left(\eta_{F e}+\eta_{i n h}\right)}
$$

Where $\chi_{F e}$ and $\chi_{\text {inh }}$ represent the electronegativity of the iron and inhibiting molecule, respectively, $\eta_{F e}$ and $\eta_{\text {inh }}$ represent the hardness of iron and the inhibiting molecule, respectively. In this study, we use the theoretical value of $\chi_{F e}=7 \mathrm{eV} / \mathrm{mole}$ and $\chi_{\text {inh }}=$ $0 \mathrm{eV} /$ mole to calculate the number of transferred electrons (Parr et al., 1999).

The value of back donation of charges is calculated using the following expression:

$$
\Delta E_{\text {Back-donation }}=\frac{\mu}{4}
$$

The electrophilicity index of the entire molecule which is given in equation 8 , measure the stabilization energy and the tendency of chemical species to obtain additional charge $\Delta N$ from the environment (Parr et al., 1999).

$$
\omega=\frac{\mu^{2}}{2 \eta}
$$

Quantitative Structural Activity Relationship (QSAR) QSAR was developed to relate the structure activity relationship of molecular descriptors from quantum chemical calculations of six phenyltetrazole derivatives as corrosion inhibitors. In this method of analysis, the quality of a model depends on the fitting and prediction ability. On this basis, it is advisable to form several quantum chemical descriptors and try to correlate the index of these quantum chemical parameters to the experimentally determined inhibition efficiencies. In this approach, a relationship is sought in the form of an equation that correlates the molecular descriptors with the observed activity. The linear equation presented by Lukovits (Lukovits et al., $2001)$ is usually used in studying corrosion inhibitors 
to enable the correlation of quantum molecular descriptors with their experimental inhibition efficiency (Lukovits et al., 2001). To build a QSAR model and test the performance of the model, the data are divided into a set used to build the model. A linear model built using selected descriptors from the data set is used to obtain the linear equation represented in Equation (9).

$$
\% \mathrm{IE}=\dot{\alpha}+\beta_{1} \mathrm{X}_{1}+\beta_{2} \mathrm{X}_{2} \ldots \ldots \ldots \beta_{\mathrm{n}} \mathrm{X}_{\mathrm{n}}
$$

$\alpha$ and $\beta$ represent the regression coefficients which are estimated from regression analysis, $X_{1}, X_{2} \ldots X_{n}$ are quantum chemical parameters of the modelled molecules.

Test of Model The model developed was validated statistically by using by using the squared fitting factor $\left(\mathrm{R}^{2}\right)$, adjusted fitting factor $\left(R_{a}^{2}\right)$, cross validation $\left(\mathrm{CV} . \mathrm{R}^{2}\right)$ and variation ratio $(\mathrm{F})$.

The adjusted fitting factor $\left(R_{a}^{2}\right)$,) defined as follows:

$$
R_{a}^{2}=\frac{(N-1) x R^{2}-P}{N-P-1}
$$

Where $\mathrm{N}$ represent the number of observations (study molecules) and $p$ is the number of descriptors,

Cross validation $\left(\mathrm{CV} . \mathrm{R}^{2}\right)$ is a mathematical method which oversees the reliability of QSAR model that can be used for a set of facts as shown in equation 11 .

$$
C V \cdot R^{2}=1-\frac{\sum\left(Y_{o b s}-Y_{c a l}\right)^{2}}{\sum\left(Y_{o b s}-\hat{Y}_{o b s}\right)^{2}}
$$

Also, a model is said to be good if the standard error of the dataset low. This standard error is defined as follows:

$$
S=\sqrt{\frac{\sum\left(Y_{o b s}-Y_{c a l}\right)^{2}}{N-p-1}}
$$

Moreover, the variance ratio $(\mathrm{F})$ measured the overall significance of the regression coefficients. It is defined as the ratio of regression mean square to deviations mean square as shown below:

$$
F=\frac{\frac{\sum\left(Y_{c a l}-\hat{Y}_{o b s}\right)^{2}}{p}}{\frac{\sum\left(Y_{o b s}-Y_{c a l}\right)^{2}}{N-p-1}}
$$

The F value has two degrees of freedom: $\mathrm{p}, \mathrm{N}-\mathrm{p}-1$. The computed $F$ value of a model should be significant at $\mathrm{p}<0.05$; thus for overall significance of the regression coefficients, the $\mathrm{F}$ value should be high.

\section{RESULTS AND DISCUSSION}

Quantum Chemical Descriptors of the Organic Inhibitors: The optimized structures of the studied molecules $\mathrm{M}_{1-6}$ using DFT functional (B3LYP/6$311 \mathrm{G}^{*}$ ) are represented in Figure 1. Electronic properties like $\mathrm{E}_{\mathrm{HOMO}}$ and $\mathrm{E}_{\mathrm{HOMO}}$ are presented in Table 1. The $\mathrm{E}_{\text {Hомо }}$ measures the electron tendency by the inhibiting molecule. Inhibiting molecule with high value of $\mathrm{E}_{\mathrm{HOMO}}$ has tendency to donate electrons to the corresponding receptor molecule of empty molecular orbital thereby improving the adsorption and the efficiency of inhibition on the surface of the metal.
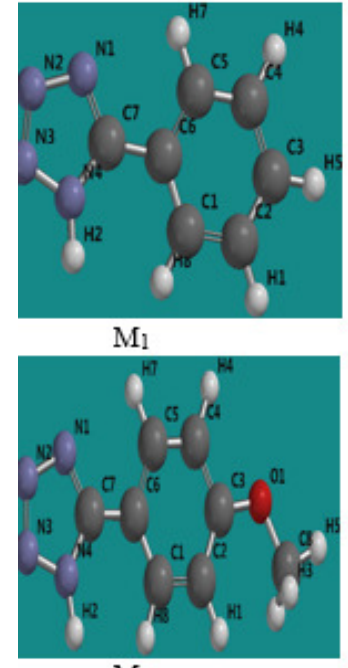

$\mathrm{M}_{3}$

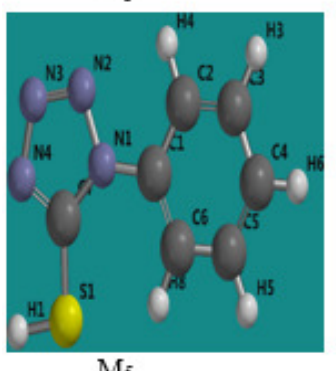

M5
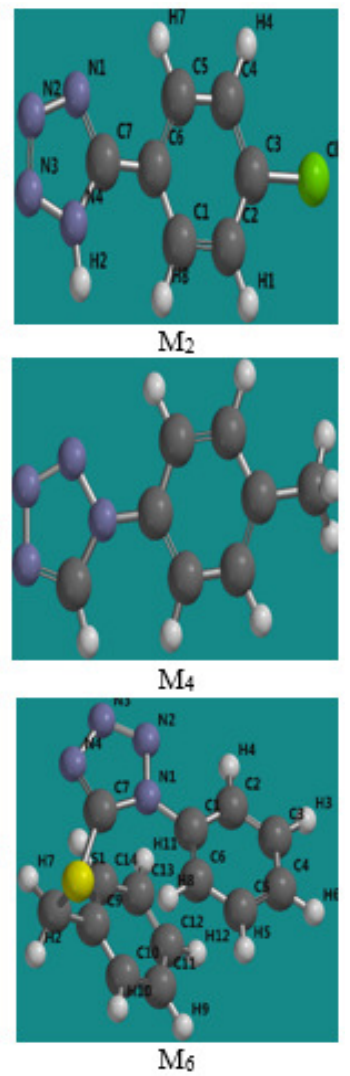

Fig 1: Optimized structures of studied molecules obtained by DFT/B3LYP/6-311G* level.

The $\mathrm{E}_{\text {номо }}$ for inhibiting molecules 1-4 are in the following order: $M_{3}>M_{2}>M_{4}>M_{1}$. This trend is similar to the sequence reported in the literature. Furthermore, the $\mathrm{E}_{\mathrm{HOMO}}$ value for the six studied molecules $\left(\mathrm{M}_{1-6}\right)$ follows $\mathrm{M}_{3}>\mathrm{M}_{6}>\mathrm{M}_{2}>\mathrm{M}_{4}>\mathrm{M}_{5}>$ $\mathrm{M}_{1}$. The highest value of $\mathrm{E}_{\text {номо }}(-6.49 \mathrm{eV})$ for $\mathrm{M}_{3}$, indicated a better inhibitor that gives electrons to corresponding empty molecular orbital energy. However, inhibiting molecule not only donate electrons to the unoccupied d-orbital of the metal ion but also accept electrons from the d-orbital of the metal, which lead to the formation of feedback bond thus, the $\mathrm{E}_{\mathrm{LUMO}}$ also indicates the ability of inhibitor to accept electrons. The $\mathrm{E}_{\mathrm{LUMO}}$ for $\mathrm{M}_{1-4}$ inhibiting molecules follow the order: $M_{2}>M_{1}<M_{4}<M_{3}$. 
Table 1. Calculated Quantum Chemical Reactivity Descriptors for Molecule 1-6 calculated using DFT/B3LYP/6-311G*

\begin{tabular}{|c|c|c|c|c|c|c|}
\hline Parameter & $\mathrm{M}_{1}$ & $\mathrm{M}_{2}$ & $\mathrm{M}_{3}$ & $\mathrm{M}_{4}$ & $\mathrm{M}_{5}$ & $\mathrm{M}_{6}$ \\
\hline$\overline{\mathbf{E}_{\text {номо }}(\mathrm{eV})}$ & -7.14 & -6.90 & -6.49 & -6.91 & -7.04 & -6.85 \\
\hline $\mathbf{E}_{\text {Lumo }}(\mathrm{eV})$ & -1.75 & -1.88 & -1.45 & 1.64 & -1.75 & -1.83 \\
\hline$\Delta \mathbf{E}(\mathrm{eV})$ & 5.39 & 5.02 & 5.04 & 5.27 & 5.29 & 5.02 \\
\hline $\boldsymbol{\sigma}(\mathrm{eV})$ & 0.37 & 0.399 & 0.397 & 0.380 & 0.377 & 0.400 \\
\hline $\mathbf{n}(\mathrm{eV})$ & 2.69 & 2.51 & 2.52 & 2.64 & 2.65 & 2.50 \\
\hline$\Delta \mathbf{N}$ & 0.47 & 0.53 & 0.60 & 0.52 & 0.49 & 0.55 \\
\hline $\log P$ & 1.88 & 1.74 & 0.90 & 2.05 & 2.39 & 3.58 \\
\hline Ovality & 1.23 & 1.27 & 1.30 & 1.27 & 1.27 & 1.42 \\
\hline $\operatorname{PSA}\left(\mathrm{A}^{2}\right)$ & 51.53 & 51.57 & 58.48 & 38.01 & 37.54 & 37.64 \\
\hline$\alpha$ & 51.63 & 52.80 & 53.91 & 53.36 & 53.25 & 61.81 \\
\hline $\mathbf{E}_{\text {solv }}(\mathrm{eV})$ & -44.31 & -42.66 & -49.59 & -43.48 & -26.95 & 29.71 \\
\hline $\mathbf{I P}(\mathrm{eV})$ & 7.14 & 6.90 & 6.49 & 6.91 & 7.04 & 6.85 \\
\hline EA $(e V)$ & 1.75 & 1.88 & 1.45 & 1.64 & 1.75 & 1.83 \\
\hline $\mathbf{X}(\mathrm{eV})$ & 4.45 & 4.39 & 3.97 & 4.28 & -4.39 & -4.34 \\
\hline Ф & -3.67 & -3.84 & -3.12 & -3.48 & -3.64 & -3.75 \\
\hline $\mathbf{V}\left(\mathrm{A}^{3}\right)$ & 142.19 & 155.86 & 169.28 & 163.07 & 161.90 & 266.16 \\
\hline Area $\left(A^{2}\right)$ & 162.19 & 177.96 & 192.08 & 183.46 & 181.96 & 284.61 \\
\hline DM(debye) & 5.98 & 4.57 & 7.70 & 6.45 & 4.86 & 5.71 \\
\hline$\Delta E_{\text {back-donation }}$ & -1.11 & -1.15 & -1.07 & -1.08 & -1.10 & -1.09 \\
\hline$\%_{\text {eff(exp) }}$ & $80^{\mathrm{a}}$ & $93^{\mathrm{a}}$ & $83^{a}$ & $82^{\mathrm{a}}$ & - & - \\
\hline
\end{tabular}

Note: $\eta=$ chemical hardness, $\omega=$ global nucleophilicity, $D M=$ dipole moment, $\Delta E=$ energy difference, $\chi=$ electrone gativity, $\sigma=$ softness, $\Delta N=$ Electron transfer, $E_{\text {solv }}=$ salvation energy, $P S A=$ polar surface area $. V=$ Volume, and ' $a$ ' = experimental inhibition efficiency was taken from El kacimi et al., 2012.

The analyses of the distribution of electron density on molecular orbitals (HOMO and LUMO) are shown in Figure 2. The electron density distribution on HOMO and LUMO localizes on the atoms of both aromatic rings and substituents of the six studied molecules. Frontier molecular orbital theory (FMO) of chemical reactivity explained that electron transition is due to the interaction between HOMO and LUMO of reacting systems (Musa, et al., 2009). The energy difference $(\Delta \mathrm{E})$ between the $\mathrm{E}_{\text {HOMO }}$ and $\mathrm{E}_{\mathrm{LUMO}}$ of a molecule relates the reactivity of the inhibiting molecule towards the adsorption on the surface of a metal. A decrease in $\Delta \mathrm{E}$ value of an inhibitor increases the binding ability to inhibit on the surface of a metal. Consequently, the reactivity of the molecule increases, which leads to an increase in inhibition efficiency (\%IE) of the molecule, since the energy for removing an electron from the last occupied orbital will be low. The value of $\Delta \mathrm{E}$ shown in Table 1 indicated that $\mathrm{M}_{1}>$ $M_{4}>M_{3}>M_{2}$, which suggests that the inhibitor $M_{2}$ has the lowest energy gap, higher reactivity and therefore, better performance than other molecules. $\Delta \mathrm{E}$ for the six studied molecules decreases in the following order: $\mathrm{M}_{2} \approx \mathrm{M}_{6}<\mathrm{M}_{3}<\mathrm{M}_{4}<\mathrm{M}_{4}>\mathrm{M}_{5}<\mathrm{M}_{1}$ Absolute hardness and softness are the quantum reactivity descriptors associated with the description of hard and soft solutions through the theory of acid and base (Kabanda et al., 2012). They are important to estimate reactivity and molecular stability. Chemical hardness indicates resistance to deformation or polarization of the electron cloud of molecules, atoms or ions with minor perturbations of the chemical reaction.

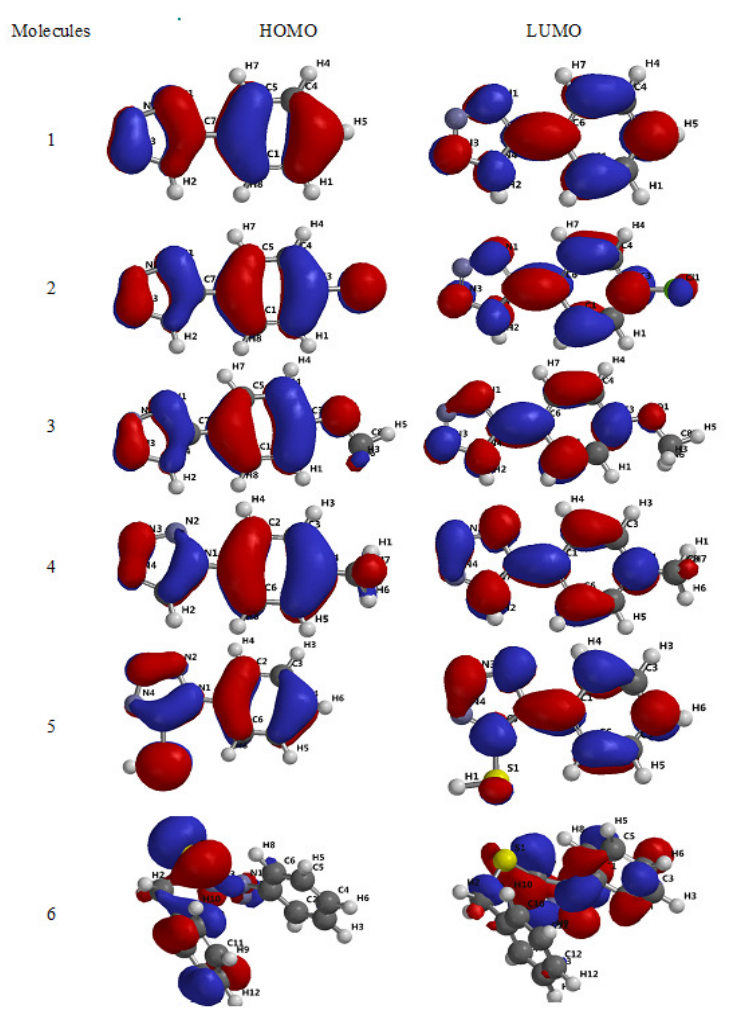

Fig 2: Frontier molecule orbital density distribution of the studied molecules: HOMO (right), LUMO (left).

The hardness order for $\mathrm{M}_{1-4}$ is as follows: $\mathrm{M}_{2}<\mathrm{M}_{3}<$ $\mathrm{M}_{4}<\mathrm{M}_{1}$. This result is consistent with the general belief that hard molecules should have large energy gap, and a soft molecule should have small energy gap (Obi-Egbedi et al., 2011). However, the global hardness for the six molecules studied decreases in the following order: $\mathrm{M}_{2} \approx \mathrm{M}_{6}<\mathrm{M}_{3}<\mathrm{M}_{4}<\mathrm{M}_{5}<\mathrm{M}_{1} . \mathrm{M}_{2}$ 
with a low hardness value of $2.51 \mathrm{eV}$ compared with other compounds also has the lowest energy gap and hence the highest inhibition efficiency since the lowest global hardness value (that is, the highest global softness value) is expected to have the highest inhibition efficiency. The softness of the studied molecules using DFT is in decreasing order of $\mathrm{M}_{2}>$ $M_{3}>M_{4}>M_{1}$. This trend correspond to the experimental inhibition efficiency of the studied compounds (El-kacimi et al., 2012) while the softness for $M_{1-6}$ is as follows: $M_{1}<M_{5}<M_{4}<M_{3}<M_{2}<M_{6}$.

The electronegativity values of studied molecules $\mathrm{M}_{1-}$ ${ }_{6}$ (Table 1) are: $\mathrm{M}_{1}>\mathrm{M}_{2}>\mathrm{M}_{4}>\mathrm{M}_{3}$. Conversely, the difference in electronegativity between the inhibiting molecule and the metal is in reverse order $\left(M_{3}>M_{4}>\right.$ $\mathbf{M}_{2}>\mathbf{M}_{1}$ ). Using Sanderson's electronegativity equalization principle (Geerlings and De-Proft, 2002), M1 with low electronegativity difference and high electronegativity value is predicted to quickly reach equalization and therefore, low reactivity is expected which in turn indicates low inhibition efficiency.

The dipole moment (DM in debye) predicts the direction of the corrosion inhibition process and gives information about the polarity (hydrophobicity) in the bond of a molecule and therefore, about the distribution of electrons in the molecules (Ebenso et al., 2010). High value dipole moment inhibitors tend to increase their adsorption on the surface of the metal to give a better inhibition because deformability energy increases with $\mu$, their molecules are more easily adsorbed at the surface of a metal. The high dipole moment for $\mathrm{M}_{3}$ and $\mathrm{M}_{6}$ (7.70 and 5.71 debye) gave good inhibition efficiency. However, there is no correlation between dipole moment and experimental inhibition efficiency of the studied compounds. Moreover, there is no direct relationship between the $\mathrm{E}_{\text {номо }}$ and the dipole moment. Similarly, there is no connection between the surface area and observed corrosion inhibition efficiency.

The number of electrons transferred $(\Delta N)$ is an indication of the ability of a molecule to donate electrons to the metal surface. The $\Delta N$ values for the six studied molecules range from $0.47-0.58$ e. Higher value of $\Delta \mathrm{N}$ in a molecule, indicate greater tendency to donate electrons to the electron deficient site and consequently, the greater the tendency to interact and adsorb at the metal surface. For the molecules $\mathrm{M}_{1-4}$, the largest proportion of electron transferred $(\Delta \mathrm{N})$ is associated with molecule $\mathrm{M}_{3}$, while the lowest proportion is associated with M1 which has the lowest inhibition efficiency. $\Delta N$ for molecules $\mathrm{M}_{1-6}$ increases in the following order: $\mathrm{M}_{3}>\mathrm{M}_{6}>\mathrm{M}_{3}>\mathrm{M}_{4}>\mathrm{M}_{5}>\mathrm{M}_{1}$. The results indicate that the $\Delta N$ values are strongly influenced by the molecular structure and substituent groups attached to the skeletal ring. In a simple model of charge transfer for donation and back donation of charges (Adardour et al., 2013), an electronic back donation process can be as a result of the interaction between the inhibiting molecule and the surface of a metal. The concept state that if both charge transfer, to the molecule and back-donation processes from the molecule occur, the change in energy is directly proportional to the hardness of the molecule, as shown in equation 7. Back donation charges $\left(\Delta E_{\text {Back-donation }}\right)$, for the studied molecules are less than zero ( -1.07 to $-1.17 \mathrm{e}$ ) indicating that the charges transferred to the molecules, accompanied by a backdonation from the molecule, is energetically favoured since $\eta>0$ and $\Delta E_{\text {Back-donation }}<0$.

Global electrophilicity index $(\omega)$ provides information on the nucleophilicity and electrophilicity nature of inhibiting molecule. Inhibitor with a high electrophilic value indicates high tendency to act as an electrophile while a low electophilicity indicates a high tendency to act as a nucleophile. A reactive nucleophile is characterized by lower electrophilicity index $(\omega)$ values and conversely, a good electrophile is characterized by a high $\omega$ values. The electrophilicity values (in Table 1) are such that $\mathbf{M}_{2}>\mathrm{M}_{6}>\mathrm{M}_{1}>\mathrm{M}_{5}$ $>\mathrm{M}_{4}>\mathrm{M}_{3}$.

QSAR modeling: The inhibition efficiencies (IE Exp \%) of the phenyltetrazole derivatives 1-4 have been determined experimentally using potentiodynamic polarization studies (El-kacimi et al., 2012). However, theoretical inhibition efficiencies of studied molecules $\left(\mathrm{M}_{1-6}\right)$ were predicted using quantitative structure activity relationships (QSAR) model (equation 14) developed via linear regression of molecular descriptors (Tables 1) calculated with DFT/B3LYB/6$31 \mathrm{G}^{*}$ methods at ambient temperature which served as independent variables and the experimentally observed inhibitory efficiencies (IE\%) against steel which are the dependent variables. Pearson's matrix was used for the selection of suitable descriptors for the QSAR study (Table 2). The selected descriptors were used to build a linear QSAR model to understand how linear regression equations can explain the structural key points correlating to differential behavior in chemical descriptors against corrosion. The combination of $\mathrm{E}_{\mathrm{LUMO}}, \Delta \mathrm{N}$, volume and $\log \mathrm{P}$ are the molecular descriptors that describe the corrosion inhibition of the compounds as shown in equation 14

For this model developed from QSAR study to be acceptable, its quality was evaluated by its predictabilities and fitting ability. The predicted corrosion inhibition efficiencies (\%IE) of molecule 1- 
4 were compared with their experimental \%IE as shown in Table 3. Figure 3 show the graph of experimental corrosion inhibition efficiencies (\%IE) against predicted corrosion inhibition efficiencies (\%IE) in order to give a clear and better understanding of their correlation. The developed QSAR model in equation 14, reproduced the experimental \% IE $\left(R^{2}=\right.$ (0.9984) with deviation ranging between 0.01 and 0.005 . Therefore the theoretical percentage inhibition efficiency for the studied compounds follows: $\mathrm{M}_{2}>$ $M_{6}>M_{3}>M_{5}>M_{4}>M_{1}$. Statistical validation of the model by using by using the squared fitting factor $\left(\mathrm{R}^{2}\right)$, adjusted fitting factor $\left(R_{a}^{2}\right)$, cross validation $\left(\mathrm{CV} \cdot \mathrm{R}^{2}\right)$ and variation ratio $(\mathrm{F})$ were also carried out. From the results obtained from the validation test, the developed models were very robust in predicting satisfactory the experimental values. The high values of $F, R^{2}, C V \cdot R^{2}$ and $R_{a}^{2}$ as shown in Table 4 indicated that the models are statistically acceptable and also have good external predictability. The calculated $\mathrm{R}^{2}$ is 0.9984; this revealed a reasonable fitness, and it also uncovered the efficiency of the model as displayed in equation 14 . The value for CV.R ${ }^{2}$ was calculated to be 0.9621 which is greater than 0.5 (standard), and this showed the reliability and acceptability of the model as well as the adjusted $\mathrm{R}^{2}$ with 0.9247 which was greater than 0.6 (Table 4).

$$
\% \mathrm{IE}=67.3+0.0609 * \text { Volume }-0.895 * \log \mathrm{P}+11.9 * \Delta \mathrm{N}-0.0517 * \mathrm{E}_{\mathrm{LUMO}} \ldots .14
$$

Table 2; Pearson's matrix used for the selection of suitable descriptors for the QSAR study

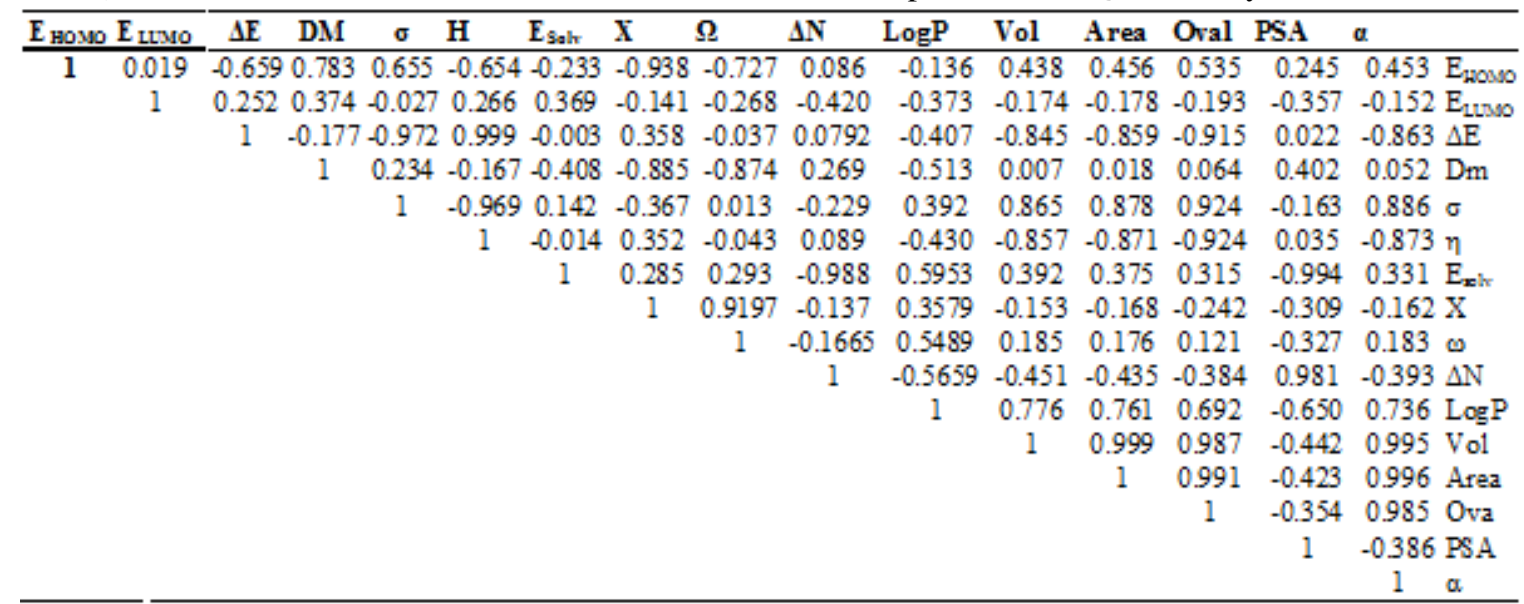

Table 3: the predicted \%IE and the experimental \%IE

\begin{tabular}{lrrr}
\hline $\begin{array}{l}\text { Molecule } \\
\mathbf{s}\end{array}$ & $\begin{array}{l}\text { Experimental\%I } \\
\mathbf{E}\end{array}$ & $\begin{array}{l}\text { predicted\%I } \\
\mathbf{E}\end{array}$ & $\begin{array}{l}\text { Deviatio } \\
\text { n }\end{array}$ \\
\hline $\mathbf{M}_{\mathbf{1}}$ & 80.00 & 80.01 & 0.01 \\
$\mathbf{M}_{\mathbf{2}}$ & 93.00 & 93.00 & -0.00 \\
$\mathbf{M}_{3}$ & 83.00 & 83.00 & -0.00 \\
$\mathbf{M}_{\mathbf{4}}$ & 82.00 & 82.05 & 0.05 \\
$\mathbf{M}_{5}$ & - & 80.94 & - \\
$\mathbf{M}_{6}$ & - & 86.94 & - \\
\hline
\end{tabular}

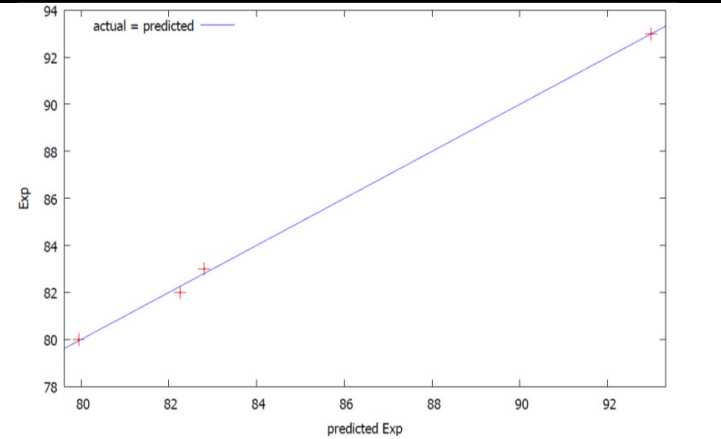

Fig 3: Correlation between experimental and predicted percentage inhibition efficiencies.

Table 4: validation test results

\begin{tabular}{llll}
\hline $\mathbf{F}$ & $\mathbf{R}^{2}$ & $\mathbf{C V} \cdot \mathbf{R}^{2}$ & $\boldsymbol{R}_{a}^{2}$ \\
\hline $\mathbf{0 . 0 0 1 5 9 6}$ & 0.9984 & 0.9621 & 0.9247 \\
\hline
\end{tabular}

Conclusion: Through DFT calculations, it is possible to establish a relationship between quantum chemical parameters of six phenyltetrazole derivatives and their effectiveness in inhibiting the corrosion process. This theoretical work show good correlation with the experimental corrosion inhibition efficiency which confirmed the reliability of the method employed in this work. The correlations and the developed model may be helpful in designing new phenyltetrazole inhibitors with suitable substitutents capable of donating electrons to the surface of a metal.

\section{REFERENCE}

Abboud, Y; Abourriche, A; Saffaj, T; Berrada, M; Charrouf, M; Bennamara, A; Al-Himidi, N; Hannache, H; (2007). 2,3-Quinoxalinedione as a novel corrosion inhibitor for mild steel in $1 \mathrm{M} \mathrm{HCl}$. Mater Chem Phys 105:1-5.

Olayemi, AM; Oyebamiji, AK; Semire, B (2016). DFT and QSAR study of corrosion inhibition on 3,5-disubstituted pyrazole derivatives with heteroatom on position one. Lebanese Sci. J.17, 2, 2016217 
Adardour, K; Touir, R; El-Bakri, M; Ramli, Y; Touhami, M; El-Kafsaoui, H; Mubengayi, C; Essassi, EM (2013). Thermodynamic study of mild steel corrosion in hydrochloric acid by new class synthesized quinoxaline derivatives: part II. Res Chem Intermed. 39: 4175-4188.

Becke, AD (1988). Density-Functional ExchangeEnergy Approximation with Correct Asymptotic Behavior. Physical Review A, Vol. 38, No. 6, pp. 3098-3100.

Chirico N, and Gramatica P (2012). Real external predictivity of QSAR models. Part 2. J Chem Inf Model; 52(8): 2044-2058.

Ebenso EE; Isabirye DA; Nnabuk OE (2010). Adsorption and quantum chemical studies on the inhibition potentials of some thiosemicarbazide for the corrosion of mild steel in acidic medium. Int. J. of Mol. Sci., 11, 2473-2498

El-Kacimi, Y; Azaroual, MA; Touir, R; Galai, M; Alaoui, K; Sfaira, M; Touhami, M; Kaya, S (2017). Corrosion inhibition studies for mild steel in $5.0 \mathrm{M}$ $\mathrm{HCl}$ by substituted phenyltetrazole. Euro-Mediterr. J. Environ Integr 2:1

El-kacimi, Y; Achnin, M; Aouine, Y; Touhami, M; Alami, A; Touir, R; Sfaira, M; Chebabe, D; Elachqar, A; Hammouti, B (2012). Inhibition of mild steel corrosion by some phenyltetrazole substituted compounds in hydrochloric acid. Port Electrochim Acta 30:53-65.

El-Sayed, H; El-Ashry, A; El-Nemra, A; Samy, A; Essawy, B; Ragaba, S (2008). Corrosion inhibitors part V: QSAR of benzimidazole and 2-substituted derivatives as corrosion inhibitors by using the quantum chemical parameters. Progress in Organic Coatings, 61 11-20

Ergun, U; Yuzer, D; Emregul, C (2008). The inhibitory effect of bis-2,6-(3,5-dimethylpyrazolyl)pyridine on the corrosion behavior of mild steel in $\mathrm{HCl}$ solution. Mater. Chem. Phys. 109, 492-499.

Geerlings, P; De Proft F (2002). Chemical Reactivity as Described by Quantum Chemical Methods. Int. J. Mol. Sci., , 3, 276.

Kabanda, MM; Shukla, SK.; Singh, AK.; Murulana, LC; Ebenso E E (2012). Electrochemical and quantum chemical studies on calmagite and fast sulphone black $\mathrm{F}$ dyes as corrosion inhibition for mild steel in hydrochloric medium. Int. J. Electrochem. Sci., 7, 8813-8831.
Kumpawat, N; Chaturvedi, A;. Upadhyay RK (2010). Protection of Metals and Physical Chemistry of Surface. 46:267-270

Kuznestov, YI; Semiletov, AM; Chirkunov, AA (2016). Inhibition of magnesium corrosion by triazole. Int J. Corros. Scale Inhib., 5: 31.

Lee, C; Yang, W; Parr, RG (1988). Development of the Collesalvetti Correlation-Energy Formula into a Functional of the Electron Density. Phys Rev. B, 37, 2, 785-789.

Lukovits, I; Kalman, E; Zucchi, F (2001). Corrosion Inhibitors: Correlation between Electronic Structure and Efficiency. Corros. Sci., 57: 3.

Musa, AY; Kadhum, AA; Mohamad, AB; Daud, AR; Takriff, MS; Kamarudin SK (2009). A comparative study of the corrosion inhibition of mild steel in sulphuric acid by 4,4-dimethyloxazolidine-2-thione. Corros Sci., 51,10, 2393-2399,

Obi-Egbedi, NO.; Obot, IB; El-Khaiary, MI; Umoren, SA; Ebsnso, EE (2011). Computational Simulation and Statistical Analysis on the Relationship Between Corrosion Inhibition Efficiency and Molecular Structure of Some Phenanthroline Derivatives on Mild Steel Surface. Int. J. Electrochem., 6, 5649.

Ojo, FK; Adejoro, IA; Akpomie, KG; Ogunyemi, BT; Oyeka, EE (2018). Effect of Iodide Ions on the Inhibitive Performance of O-, M-, P-Nitroaniline on Mild Steel in Hydrochloric Acid Solution. J. Appl. Sci. Environ. Manage. 22 (5) 775- 782

Parr, RG and Pearson, RG (1983), Absolute Hardness: Companion Parameter to Absolute Electronegativity. J. Am. Chem. Soc., 105, 26 75127516.

Parr, RG; Szentpaly, LV; Liu, S (1999). Electrophilicity Index. J. Am. Chem. Soc, 121 (9) 1922-1924.

Pearson, RG (1986). Absolute Electronegativity and Hardness Correlated with Molecular Orbital Theory. Proceedings of the National Academy of Sciences of the United States of America, 83, 8440-8441.

Shao, Y; et al (More than 30 authors) (2011). SPARTAN'10, build 1.01, Wavefunction Inc. Irvine CA 